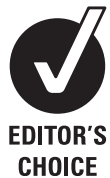

Jefferiss Trust Laboratories, Wright-Fleming Institute, Imperial College London, London, UK

Correspondence to Dr Craig Tipple, Clinical Research Fellow, Jefferiss Trust Laboratories, Wright-Fleming Institute, Imperial College London, Norfolk Place, London W2 1PG, UK c.tipple@imperial.ac.uk

Accepted 19 July 2011

\title{
High prevalence of macrolide resistant Treponema pallidum strains in a London centre
}

\author{
Craig Tipple, Myra 0 McClure, Graham P Taylor
}

ABSTRACT

Objectives Macrolide resistant Treponema pallidum strains, caused by mutations in the $23 \mathrm{~S}$ ribosomal RNA (23S rRNA) gene, are widespread and increasingly prevalent. The authors aimed to establish the strain types of $T$ pallidum isolated from patients in a London sexual health centre and to determine the frequency of macrolide resistance.

Methods $T$ pallidum DNA from blood and ulcer samples were subjected to strain typing and mutation analysis using previously described methods.

Results 18 samples were tested and a 23S rRNA point mutation conferring macrolide resistance was found in $66.6 \%$. All resistant strains were collected from men who have sex with men and both the A2058G and the A2059G mutations were found. Two strain types were identified $(14 \mathrm{~d} / \mathrm{g}$ and $14 \mathrm{~d} / \mathrm{f})$; the predominant strain type was $14 \mathrm{~d} / \mathrm{g}$ and an association was noted between tp0548 type $\mathrm{g}$ and macrolide resistance.

Conclusions High levels of $T$ pallidum macrolide resistance are present in London, UK, and this has clear implications for national treatment guidelines.

\section{INTRODUCTION}

British guidelines for the management of syphilis include macrolide antibiotics as alternative treatments for incubating and early disease. ${ }^{1}$ This advice comes with the caveat that intrinsic macrolide resistance is present in some strains of Treponema pallidum, although the UK prevalence is unknown.

Following trials showing comparable efficacy to benzathine penicillin, single-dose azithromycin was adopted for the treatment of incubating and early disease. $^{2}{ }^{3}$ This was followed by reports of treatment failures, mostly among men who have sex with men (MSM), attributed to a single point mutation in the $T$ pallidum $23 \mathrm{~S}$ ribosomal RNA (23S $r R N A$ ) gene, a mutation that is now geographically widespread and increasingly prevalent. ${ }^{3} 4$

In addition to the detection of resistance mutations, molecular analysis of $T$ pallidum allows the identification of different strains and while there are common types, considerable diversity within epidemics has been demonstrated. ${ }^{5}$

In this study, we present genotypic evidence of macrolide resistance and strain typing data from London, UK.

\section{METHODS}

\section{Study participants and specimens}

Samples were collected from patients attending St Mary's Hospital, London (July 2006-January 2008) in a cross-sectional study of $T$ pallidum infection following ethical approval from the Hounslow and Hillingdon Research Ethics Committee. ${ }^{6}$

\section{S rRNA mutation detection}

As previously described, a section from each copy of the $T$ pallidum 23S rRNA gene (Genbank ref. AF200367) was PCR-amplified from extracted DNA. ${ }^{4}$ Separate aliquots of each amplicon were digested using the restriction endonucleases $M b o-I I$ and $B s a-I$ and the resultant digestion pattern was analysed. ${ }^{4}$ For confirmation, the gene sequence of a third (undigested) aliquot was determined using the Applied Biosystems dRhodamine kit and 3100 capillary sequencer.

Plasmids containing DNA from Street 14 strain (an A2058G mutant obtained from a patient who failed macrolide therapy) or UW228B (A2059G mutant) constituted positive controls for both the initial PCR and the enzymatic digestion.

\section{Strain typing}

Identification of strains was based on the arp, tpr and tp0548 genes, as described. ${ }^{4}$ To summarise: following PCR amplification, the size of the arp amplicons, determined by agarose gel electrophoresis, is compared with Nichols strain $T$ pallidum, which is known to contain 14 repeats of a 60 base pair sequence. The number of repeats forms the first part of the type $(14,15$, etc). The second part requires $M s e-1$ restriction digestion of the $t p r$ amplicon for comparison of the resulting digestion pattern with standard profiles. Each pattern is assigned a letter ( $a, b$, etc). Finally, the sequence of the tp0548 gene amplicon is compared with one of a number of previously established sequences $(a, b$, etc).

\section{RESULTS}

$T$ pallidum from 18 patients was available for analysis. All subjects were male, median age 37 years (range 24-54) and 61.1\% were HIV-1 positive (table 1). Where sexual orientation was stated, $94.1 \%$ were MSM.

\section{S rRNA mutation analysis}

$23 \mathrm{~S}$ rRNA mutations were identified in 12/18 (66.6\%) samples of which 11 had the A2058G substitution (table 1). All 23s rRNA mutations were present in both copies of the gene.

\section{Strain subtype analysis}

Twelve samples had sufficient DNA remaining for strain-type analysis, resulting in the identification of five full and seven partial strain types (table 1). Where analysis of arp and tpr genes succeeded, only the $14 \mathrm{~d}$ type was detected. Sequence analysis of the tp0548 gene classified these as $14 \mathrm{~d} / \mathrm{g}$ (four isolates) and $14 \mathrm{~d} / \mathrm{f}$ (one isolate) strains. 
Table 1 Demographic, typing and mutation data

\begin{tabular}{|c|c|c|c|c|c|c|c|c|c|c|}
\hline $\begin{array}{l}\text { Case } \\
\text { number }\end{array}$ & $\begin{array}{l}\text { Age } \\
\text { (years) }\end{array}$ & $\begin{array}{l}\text { Sexual } \\
\text { orientation }\end{array}$ & $\begin{array}{l}\text { HIV-1 } \\
\text { status }\end{array}$ & $\begin{array}{l}\text { Stage of } \\
\text { disease }\end{array}$ & $\begin{array}{l}\text { Sample } \\
\text { type }\end{array}$ & $\begin{array}{l}\text { Number of } \\
\text { arp repeats }\end{array}$ & $\begin{array}{l}\text { tpr gene mse-1 } \\
\text { digest pattern }\end{array}$ & $\begin{array}{l}\text { tp0548 } \\
\text { sequence }\end{array}$ & $\begin{array}{l}\text { Full strain } \\
\text { type }\end{array}$ & $\begin{array}{l}\text { 23S rRNA } \\
\text { type }\end{array}$ \\
\hline 1 & 31 & Homosexual & Negative & Secondary & Ulcer & - & $\mathrm{d}$ & $\mathrm{g}$ & - & A2058G \\
\hline 2 & 34 & Homosexual & Negative & Primary & Ulcer & 14 & $d$ & $\mathrm{~g}$ & $14 \mathrm{~d} / \mathrm{g}$ & A2058G \\
\hline 3 & 50 & Homosexual & Negative & Primary & Ulcer & 14 & $d$ & $\mathrm{~g}$ & $14 \mathrm{~d} / \mathrm{g}$ & A2058G \\
\hline 4 & 24 & - & Positive & Primary & Ulcer & - & - & - & - & Wild-type \\
\hline 5 & 43 & Homosexual & Positive & Secondary & Blood & - & - & - & - & A2058G \\
\hline 6 & 38 & Homosexual & Positive & Primary & Ulcer & 14 & $d$ & $\mathrm{~g}$ & $14 d / g$ & A2058G \\
\hline 7 & 28 & Homosexual & Negative & Primary & Ulcer & - & - & g & - & A2058G \\
\hline 8 & 42 & Homosexual & Positive & Secondary & Ulcer & - & - & $f$ & - & Wild-type \\
\hline 9 & 41 & Homosexual & Positive & Secondary & Blood & - & - & - & - & A2058G \\
\hline 10 & 33 & Homosexual & Positive & Primary & Ulcer & 14 & $\mathrm{~d}$ & $f$ & $14 d / f$ & A2058G \\
\hline 11 & 38 & Homosexual & Positive & Secondary & Blood & - & - & - & - & Wild-type \\
\hline 12 & 30 & Homosexual & Positive & Secondary & Blood & - & - & - & - & A2058G \\
\hline 13 & 54 & Heterosexual & Positive & Primary & Ulcer & 14 & - & $f$ & - & Wild-type \\
\hline 14 & 30 & Homosexual & Negative & Primary & Ulcer & - & - & $\mathrm{g}$ & - & A2058G \\
\hline 15 & 45 & Homosexual & Positive & Secondary & Blood & - & - & - & - & A2059G \\
\hline 16 & 36 & Homosexual & Positive & Primary & Ulcer & 14 & $d$ & $\mathrm{~g}$ & $14 d / g$ & A2058G \\
\hline 17 & 47 & Homosexual & Negative & Primary & Ulcer & 14 & - & $f$ & - & Wild-type \\
\hline 18 & 31 & Homosexual & Negative & Primary & Ulcer & - & - & $f$ & - & Wild-type \\
\hline
\end{tabular}

23S rRNA, 23S ribosomal RNA.

In total, 7 of the 12 tp0548 gene sequences were ' $g$ ' and the remaining 5 were ' $\mathrm{f}$ ' of which 4 had wild-type $23 \mathrm{~S}$ rRNA sequences and 1 was an A2058G mutant.

No association was identified between HIV-1 status and either full $T$ pallidum subtype or type according to tp0548 sequence alone.

\section{DISCUSSION}

White MSM account for around three-quarters of syphilis cases in the UK and HIV-1 co-infection (34\%) is common. ${ }^{8}$ Patients with early syphilis participating in this study (2006-2008) were also predominantly white MSM (94.1\%); 61.1\% were HIV-1 positive and two-thirds of the $T$ pallidum isolates had genotypic evidence of resistance to macrolide antibiotics. These findings, the first such data from the UK, have implications for syphilis treatment guidelines. ${ }^{1}$

In San Francisco, the prevalence of resistant strains increased from $4 \%$ in $2000-2002$ to $56 \%$ in 2004 . This coincided with guidelines that included the use of azithromycin as an alternative for the treatment of incubating and subsequently early syphilis. ${ }^{3}$ While azithromycin has never been the preferred therapy for the management of syphilis in the UK, it has been increasingly prescribed for the treatment of nonspecific urethritis and chlamydia. Samples prior to 2006 were not available to assess changes in the prevalence of resistant strains.

\section{Key messages}

- In two thirds of syphilis cases seen at our London centre, the causative Treponema pallidum has a mutation conferring high-level macrolide resistance.

- The recent increase in Treponema pallidum infections is driven by more than one strain.

- Macrolide antibiotics should be avoided for the treatment of incubating or early syphilis, especially for gay men in London.
The suggestion that a single resistant strain may enter a population and become endemic is supported by evidence that the $23 S r R N A$ mutation in the Street 14 strain is stable, when passaged in untreated rabbits. ${ }^{59}$ In this scenario, a mutant strain would have been imported into the London MSM population where it became the predominant circulating strain. If all the $23 S$ rRNA mutants were a single clone, we would expect only one subtype. However, subtype analysis from this and other studies presents a more complex picture. Four of the full subtypes identified were $14 \mathrm{~d} / \mathrm{g}$ and the fifth was $14 \mathrm{~d} / \mathrm{f}$. The higher level of success achieved by typing $T$ pallidum from ulcer samples than from blood probably reflects the relative bacterial loads. ${ }^{6}$ While the number of full subtypes identified in this study was limited, other molecular epidemiology studies of syphilis in Scotland and Canada have identified several subtypes within these populations. ${ }^{5} 10$ It seems likely, therefore, that neither these epidemics nor the London epidemic represent the spread of a single clone, and a significant role for antibiotic selection pressure is suggested. This is supported by epidemiological evidence that macrolide exposure in the 3 months prior to syphilis diagnosis is associated with a $30 \%$ increase in resistance. $^{9}$

In summary, we have shown that genotypic macrolide resistance in $T$ pallidum is common in MSM in London and, therefore, we recommend caution in the use of macrolides for the treatment of syphilis, particularly in this MSM population. Although limited, our typing data suggest that the syphilis epidemic in London is not a single clone of resistant $T$ pallidum, raising the possibility that resistance mutations are developing de novo.

Acknowledgements The authors thank Professor Sheila Lukehart, University of Washington, Seattle, for donation of samples and advice.

Funding This study was supported by the Mason Medical Foundation and the Imperial College Healthcare Biomedical Research Centre.

\section{Competing interests None.}

Ethics approval This study was conducted with the approval of Hounslow and Hillingdon REC.

Contributors CT: undertook the experimental work described, analysed the data, wrote the first draft of the manuscript and approved the final published version. MOM: study 
concept and design, critical revision of the manuscript for scientific concept and approved the final published version. GPT: Study concept and design, critical revision of the manuscript for scientific concept and approved the final published version.

Provenance and peer review Not commissioned; externally peer reviewed.

\section{REFERENCES}

1. Kingston M, French P, Goh B, et al. UK National Guidelines on the Management of Syphilis 2008. Int J STD AIDS 2008;19:729-40.

2. Riedner G, Rusizoka M, Todd J, et al. Single-dose azithromycin versus penicillin G benzathine for the treatment of early syphilis. N Engl J Med 2005;353:1236-44.

3. Katz KA, Klausner JD. Azithromycin resistance in Treponema pallidum. Curr Opin Infect Dis 2008:21:83-91.

4. Lukehart S, Godornes C, Molini B, et al. Macrolide resistance in Treponema pallidum in the United States and Ireland. N Engl J Med 2004;351:154-8.
5. Cole M, Chisholm S, Palmer $\mathrm{H}$, et al. Molecular epidemiology of syphilis in Scotland Sex Transm Infect 2009;85:447-51.

6. Tipple C, Hanna M, Hill S, et al. Getting the measure of syphilis: qPCR to better understand early infection. Sex Transm Infect 2011:87:479-85.

7. Matejková $\mathbf{P}$, Flasarová $M$, Zákoucká $H$, et al. Macrolide treatment failure in a case of secondary syphilis: a novel A2059G mutation in the 23S rRNA gene of Treponema pallidum subsp. pallidum. J Med Microbiol 2009;58:832-6.

8. Health Protection Agency UK. Syphilis and Lymphogranuloma Venereum: Resurgent Sexually Transmitted Infections in the UK, 2009. http://www.hpa.org.uk/ webc/HPAwebFile/HPAweb_C/1245581513523 (accessed 23 Jun 2011).

9. Marra CM, Colina AP, Goōornes C, et al. Antibiotic selection may contribute to increases in macrolide-resistant Treponema pallidum. J Infect Dis 2006;194:1771-3.

10. Martin IE, Tsang RS, Sutherland K, et al. Molecular typing of Treponema pallidum strains in western Canada: predominance of $14 \mathrm{~d}$ subtypes. Sex Transm Dis 2010;37:544-8.

\section{Letter}

Assessing the understanding and prior uptake of human papillomavirus vaccination among eligible females attending genitourinary medicine clinics in UK

In 2008, the UK human papillomavirus vaccination programme was introduced to vaccinate all 12-13-year-old girls, with a 2-year catch up for those aged up to 18 years. Delivery has been principally through schools and general practitioners, although concern remains that all groups are not being reached and the full three doses may not be received by all. Many young sexually active females attend genitourinary medicine (GUM) clinics; therefore, this may be a potential location for vaccine delivery.

In order to assess knowledge and prior vaccine uptake, a survey was conducted in five UK GUM clinics. A questionnaire and information leaflet was approved by the Northern Ireland Research Committee and distributed from August to December 2009. Eligible females were those born between the years 1990 and 1996 inclusive (ie, aged $12-18$ years when the programme was introduced). Questionnaires were distributed by the reception staff to consecutive patients and completed unsupervised.

Five-hundred and fifty-eight questionnaires were returned; however, 65 (12\%) were excluded due to incomplete data. Of the remaining 493, 25 (5\%) were aged under 15 years, 241 (49\%) $15-16$ years and 227
(46\%) 17-18 years old. The majority (85\%) of respondents had heard of the human papillomavirus vaccine; however, only $26 \%$ had received one or more doses. Only $40 \%$ of those who received the vaccine knew which vaccine was given. Ninety per cent stated they would accept the vaccine if offered at a GUM clinic and, given the choice, 13\% would prefer Cervarix, 38\% Gardasil and $49 \%$ remained unsure.

It appears health promotion strategies have been effective given that the majority of respondents were aware of the programme; however, the uncertainty regarding which vaccine was received suggests information disseminated about the two commercially available vaccines has not been grasped. After reading the information provided, those who made a choice showed a clear preference for Gardasil.

Vaccine uptake among those surveyed is disappointing and falls short of the Department of Health figures. ${ }^{1}$ Given the large number of young sexually active females attending GUM clinics, it would appear an ideal location for participation and improve vaccine uptake.

Recent sexually transmitted infection figures from GUM clinics in UK show a continuing increasing trend of infections. ${ }^{2}$ There is an opportunity for a major contribution to disease prevention by considering quadrivalent vaccine. Evidence from Australia of the reducing prevalence of genital warts further strengthens this argument. ${ }^{3}$ The next round of UK contracting is imminent and we would urge switching to quadrivalent vaccine to maximise programme benefits and relieve the evergrowing pressure on GUM services.

\section{E J McCarty, ${ }^{1}$ C 0'Mahony, ${ }^{2}$ S Bates, ${ }^{3}$ P Fox, ${ }^{4}$ R D Maw ${ }^{1}$}

'Department of Genitourinary Medicine, Royal Victoria Hospital, Belfast Health and Social Care Trust, UK; ${ }^{2}$ Department of Genitourinary Medicine, Countess of Chester Foundation Trust Hospital, Chester, UK; ${ }^{3}$ Department of Genitourinary Medicine, Royal Hallisham Hospital, Sheffield Teaching Hospitals, UK; ${ }^{4}$ Department of Genitourinary Medicine, Ealing Hospital, Southall, UK

Correspondence to E J McCarty, Department of Genitourinary Medicine, Royal Victoria Hospital, Grosvenor Road, Belfast BT12 6AB, UK:

ej_mccarty@hotmail.com

Competing interests None.

Ethics approval Northern Ireland Ethics Committee.

Provenance and peer review Not commissioned; internally peer reviewed.

Accepted 17 July 2011

Sex Transm Infect 2011;87:488

doi:10.1136/sextrans-2011-050142

\section{REFERENCES}

1. Health Protection Agency. Annual HPV Vaccine Uptake in England, 2008-2009. http://www.dh.gov.uk

2. Health Protection Agency. Trends in STI Diagnosis UK and England, 2008-2009. http://www.hpa.org.uk (accessed 2 Apr 2011).

3. Fairley CK, Hocking JS, Gurrin LC, et al. Rapid decline in presentations of genital warts after the implementation of a national quadrivalent human papillomavirus vaccination programme for young women. Sex Transm Infect 2009:85:499-502. 